American Journal of Applied Sciences 7 (3): 381-385, 2010

ISSN 1546-9239

(C) 2010Science Publications

\title{
Surface Bioactivity of Sol Gel Derived 3Y-TZP Bioinert Ceramic through Hydroxylation Technique Using $5 \mathrm{M} \mathrm{H}_{3} \mathrm{PO}_{4}$
}

\author{
${ }^{1}$ R. Velmurugan, ${ }^{1} \mathrm{~S}$. Kanagesan, ${ }^{1,2} \mathrm{~S}$. Jesurani and ${ }^{1} \mathrm{~T}$. Kalaivani \\ ${ }^{1}$ Center for Material Science and Nano Devices, Department of Physics, \\ SRM University, Kattankulathur 603203, India \\ ${ }^{2}$ Department of Physics, \\ Jeyaraj Annapackium College for Women, Periyakulam 626501, India
}

\begin{abstract}
Problem statement: This study presented bone like apatite formation on yttria stabilized zirconia in Simulated Body Fluid (SBF) through hydroxylation technique. Approach: Sol gel route was used to prepare yttria stabilized zirconia. Then it was hydroxylated with $5 \mathrm{M} \mathrm{H}_{3} \mathrm{PO}_{4}$ for formation of $\mathrm{Zr}-\mathrm{OH}$ group. Moreover, the growth rate of calcium and phosphate on zirconia substrate was examined using simulated body fluid. Results: From x-ray diffraction pattern, confirmed the phase formation of tetragonal zirconia. SEM analysis shows the growth of Ca-P on zirconia in SBF solution. AFM represents the particle size of Ca-P is about $68-70 \mathrm{~nm}$ for 7 days SBF and exactly $60 \mathrm{~nm}$ for 15 days SBF solution. Conclusion: The results showed that the yttria stabilized zirconia in SBF solution through hydroxylation gives better results.
\end{abstract}

Key words: Bone like apatite, yttria stabilized zirconia, simulated body fluid, hydroxylation, $\mathrm{H}_{3} \mathrm{PO}_{4}$

\section{INTRODUCTION}

The zirconia and Alumina are used extensively in dental and orthopedic implantation because of its mechanical properties and chemical resistance to degradation by bodily fluids. When a ceramic is used as a medical implant, it is important to create a stable bond between bone tissue and the surface of the implant. Poor bonding at the interface between the surface of the implant and the bone tissue leads to low mechanical strength of the bone-to-implant junction and the possibility of subsequent implant failure. An important goal for interface optimization is to use species which are biocompatible and which enable bone mineralization at the interface following implantation. Bone tissue is a combination of protein and mineral content, with the mineral content being in the form of hydroxyapatite. Currently, there is no effective way to obtain strong attachment of bone with the implant material at the interface between the surfaces of the two materials in order to stabilize the implant.

The present study mainly focused on yttria stabilized zirconia. Zirconia ceramics have been commonly used in orthopedic implant materials, Cales (2000) bidding superior corrosion and scratch resistance relative to metal and better resistance to brittle fracture than alumina. Zirconia ceramic stabilized with 3 mol\% yttria (3Y-TZP) has been used in the field of total hip arthoplasty and dentistry (Clarke et al., 2003; Kosmac et al., 2000). These kinds of bioinert bioceramics have pleasing properties, such as high strength and fracture toughness for biomedical applications (Benzaid et al., 2008; Ohtsuki et al., 1992). Howsoever, the integration between the bioinert ceramics and tissue is a critical problem. There has been considerable exertion for improving the bioactivity of zirconia inert bioceramics. Uchida et al. (2002) investigated that the effect of chemical treatments with aqueous $\mathrm{H}_{3} \mathrm{PO}_{4}, \mathrm{H}_{2} \mathrm{SO}_{4}, \mathrm{HCl}$, or $\mathrm{NaOH}$ on nano composite zirconia/alumina and found that the $\mathrm{Zr}-\mathrm{OH}$ group produced by chemical treatments improved the bioactivity of the composite and that the $\mathrm{Zr}-\mathrm{OH}$ group formed on zirconium metal only after pre heat treatment in $\geq 5 \mathrm{M}$ aqueous $\mathrm{NaOH}$ solution showed the ability to induce apatite formation in simulated body fluid. For the purpose of improving the bioactivity of the zirconia and investigate a new technique for inducing $\mathrm{OH}$ group and apatite formation (Yan and Lu, 2009; Liu and Ding, 2003; Uchida et al., 1998; 2001a; 2001b).

One molar aqueous solutions of zirconiumoxychloride and yttrium nitrate were prepared separately and they were optically filtered to remove any contamination. The two solutions were mixed and

Corresponding Author: R. Velmurugan, Center for Material Science and Nano Devices, Department of Physics, SRM University, Kattankulathur 603203, India 
Am. J. Applied Sci., 7 (3): 381-385, 2010

the homogeneous mixing was attained after stirred for $1 \mathrm{~h}$ in a magnetic stirrer. The $1 \mathrm{M}$ aqueous solution of oxalic acid was prepared and added periodically into the mixed solution of $\mathrm{ZrOCl}_{2} \cdot 9 \mathrm{H}_{2} \mathrm{O}$ and $\mathrm{Y}\left(\mathrm{NO}_{3}\right)_{2} \cdot 6 \mathrm{H}_{2} \mathrm{O}$ under stirring. The addition of oxalic acid was sensitive and a crucial one in determining the quality of gel formation. Once the oxalic acid was added, a white flocculate occurred and this turned into a clear sol by the continuous vigorous stirring. When the sol was kept at room temperature for some time, it becomes a thick transparent gel. Then, the gel becomes a thick transparent gel. Then, the gel was dried in oven at $45^{\circ} \mathrm{C}$ in air for 5 days. Once the gel was kept at low temperature for a long period, the chloride ions were removed as $\mathrm{HCl}$. The dried zirconium-oxalate gel powder was obtained by hand grounding in an agate mortar and later, this powder was calcined at $800^{\circ} \mathrm{C}$.

Preparation of test sample: For the preparation of pellets, 3 mol\% yttria stabilized zirconia was crushed into a fine powder in an acetone medium using agate mortar and dried in hot air oven. Then zirconia was thoroughly mixed with few drops of Poly Vinyl Alcohol (PVA) binder. The mixture of zirconia and PVA, thus formed, was used for pellet making. The powder was pressed into a pellet form under a pressure of nearly 3 tons using hydraulic press. The pellets were, then, sintered at $1400^{\circ} \mathrm{C}$ for about $3 \mathrm{~h}$ in the electric furnace for the removal of binder species.

Hydroxylation: The sintered 3 mol\% yttria stabilized zirconia samples were ultrasonically washed in acetone and rinsed in deionized water and then samples were immersed in $5 \mathrm{M} \mathrm{H}_{3} \mathrm{PO}_{4}$ solution at $95^{\circ} \mathrm{C}$ for 5 days. After 5 days, the test samples were taken out from hydroxylated solution washed in deionized water, the samples were soaked in the Simulated Body Fluid (SBF) solution made according to the recipe by Kokubo.

Bioactivation: To study the bioactivity, the $3 \mathrm{~mol} \%$ yttria stabilized zirconia samples were soaked in $100 \mathrm{~mL}$ of Simulated Body Fluid (SBF) with ion concentrations $\left(\mathrm{Na}^{+}\right.$142.0, K${ }^{+}$5.0, $\mathrm{Mg}^{2+}$ 1.5, $\mathrm{Ca}^{2+}$ 2.5, $\mathrm{Cl}^{-}$148.8, $\mathrm{HCO}_{3}{ }^{-} 4.2, \mathrm{HPO}^{2-} 1.0, \mathrm{SO}^{2-} 0.5 \mathrm{Mm}$ ) nearly equal to those of human blood plasma at $36.5^{\circ} \mathrm{C}$. The Simulated Body Fluid (SBF) was prepared by dissolving reagent grade chemicals of $\mathrm{NaCl}, \mathrm{NaHCO}_{3}, \mathrm{KCl}$, $\mathrm{K}_{2} \mathrm{HPO}_{4} \cdot 3 \mathrm{H}_{2} \mathrm{O}, \mathrm{MgCl}_{2} \cdot 6 \mathrm{H}_{2} \mathrm{O}, \mathrm{CaCl}_{2}$ and $\mathrm{Na}_{2} \mathrm{SO}_{4}$ into double distilled water and buffered at $\mathrm{pH} 7.40$ with trishydroxymethylamminomethane $\left(\mathrm{CH}_{2} \mathrm{OH}\right) \mathrm{CNH}_{3}$ and Hydrochloric acid $(\mathrm{HCl})$ at $36.5^{\circ} \mathrm{C}$. After soaking for 7 and 15 days, the test samples were taken out from the
Simulated Body Fluid (SBF), gently washed with distilled water and then dried in air.

\section{MATERIALS AND METHODS}

Figure 1 illustrates the transformation of crystalline phases in the process of preparing the 3Y-TZP pellet through the sol gel route, using Yttrium nitrate and Zirconium oxychloride as the starting materials. From those peaks, confirmed the structure of tetragonal zirconia $\left(\mathrm{t}-\mathrm{ZrO}_{2}\right)$, the major peaks were identified in $30.582^{\circ}, 35.409^{\circ}$ and $50.643^{\circ}$ with their corresponding hkl values are (111), (200) and (220) of two theta values for $\mathrm{t}-\mathrm{ZrO}_{2}$ as compared with standard diffraction pattern. The JCPDS number is 14-0534.

The surface morphology of the 3Y-TZP pellet substrates were immersed in Simulated Body Fluid (SBF) solution for 7 days and 15 days are displayed in Fig. 2 and 3. After 7 days immersion in SBF solution, the growth of the apatite, which covered on the surface of the zirconia substrate, was very poor. In addition, the smaller groups of few clustered particles were formed on the 3Y-TZP substrate shown in Fig. 2. After 15 days immersion in SBF solution, the growth rate of the apatite, which was maximum, covered on the surface of the zirconia substrate shown in Fig. 3.

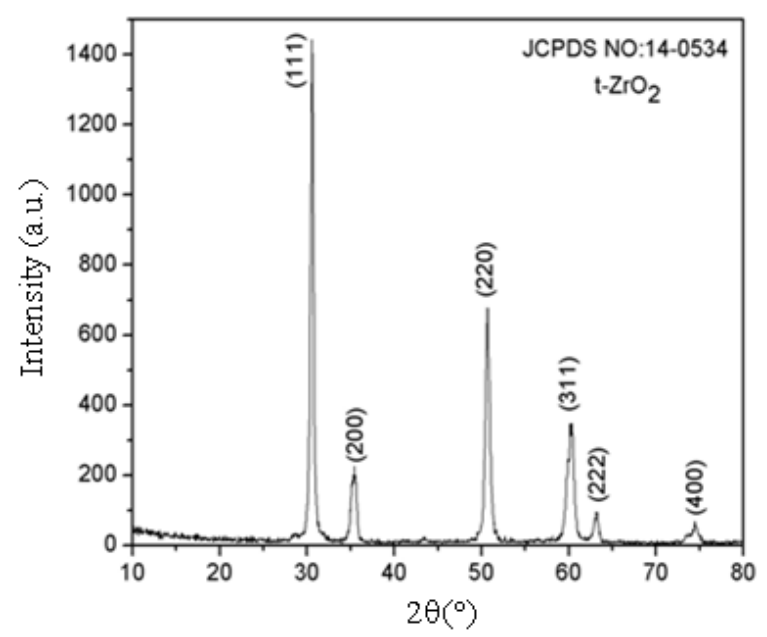

Fig. 1: XRD patterns of 3 mol\% Yttria stabilized zirconia

Table 1: Element present on Y-TZP for 7 days SBF

\begin{tabular}{lll}
\hline Element & Wt (\%) & At (\%) \\
\hline OK & 31.72 & 67.06 \\
YL & 03.94 & 01.32 \\
PK & 10.39 & 08.26 \\
ZrL & 40.16 & 13.11 \\
CaK & 13.79 & 10.25 \\
\hline
\end{tabular}




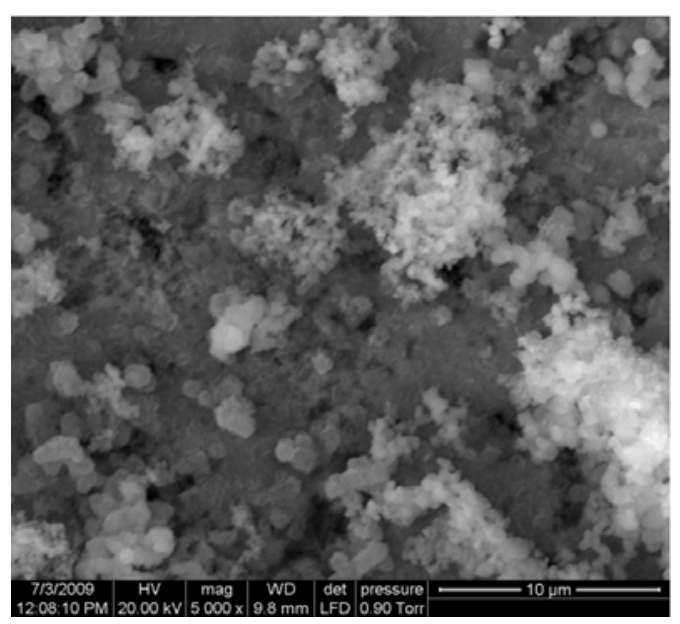

Fig. 2: SEM results of Y-TZP in SBF for 7 days

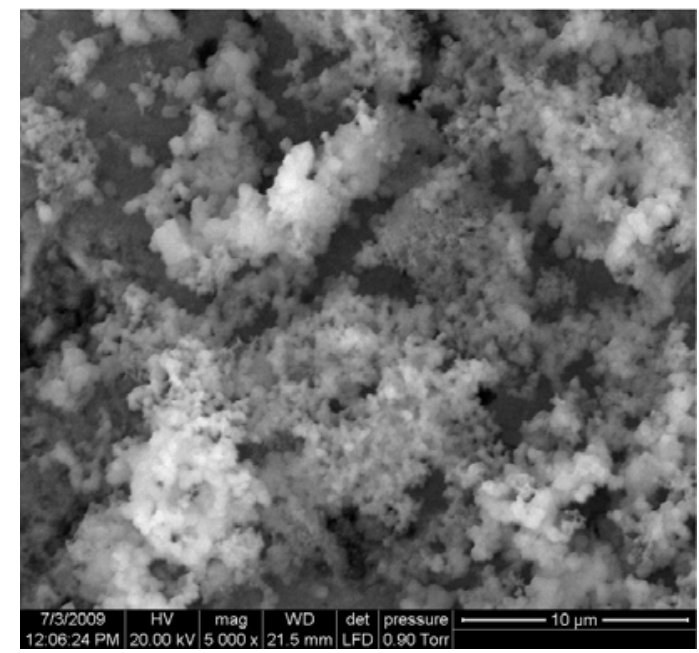

Fig. 3: SEM results of Y-TZP in SBF for 15 days

In Fig. 4 and 5 the EDX spectrum acquired from the zirconia substrate soaked in SBF solution for 7 days and 15 days revealed that the existence of calcium and phosphorous on the surface. The atomic ratio of $\mathrm{Ca} / \mathrm{P}$ calculated from the EDX spectra of the 3Y-TZP soaked in SBF solution for 7 days is about 1.24 and 15 days is about 1.46 has shown in Table 1 and 2. After 15 days in SBF solution, the atomic ratio of Ca-P is nearly equal to hydroxyapaptite $\left(\mathrm{Ca}_{10}\left(\mathrm{PO}_{4}\right) 6(\mathrm{OH})_{2}\right)$. Figure 6 shows the AFM line profile of the bone like apatite formation on yttria stabilized zirconia substrate for 7 days SBF, the particles shape were spherical and measurement of particle size was 68-70 nm range and of uniform size. After global fitting, line profile was taken for 15 days SBF, the size of the particle was $60 \mathrm{~nm}$ is shown in Fig. 7.

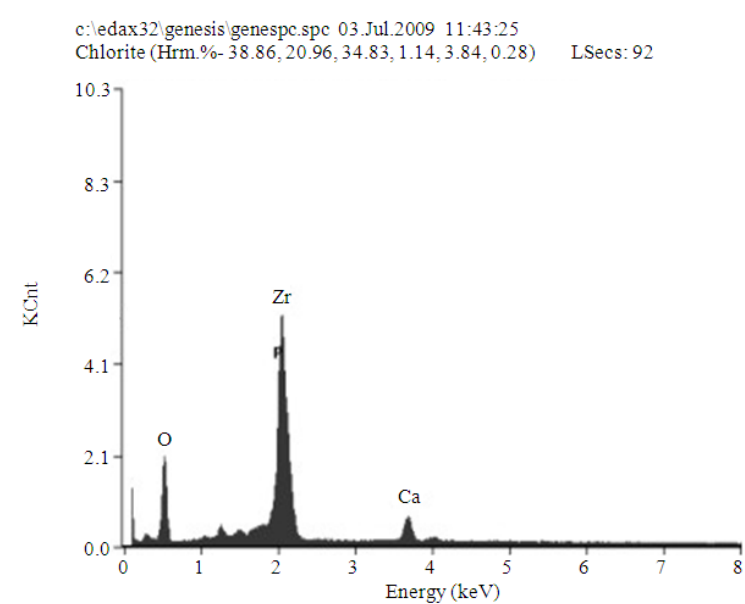

Fig. 4: EDX results of Y-TZP in SBF for 7 days

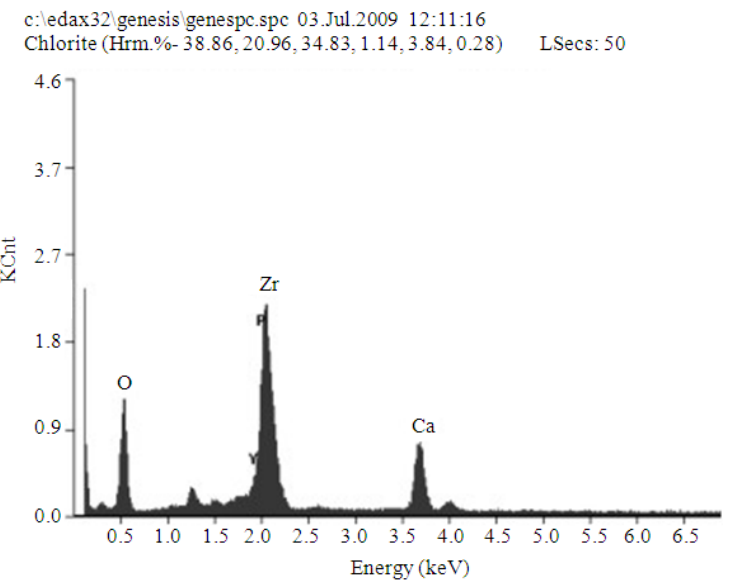

Fig. 5: EDX results of Y-TZP in SBF for 15 days
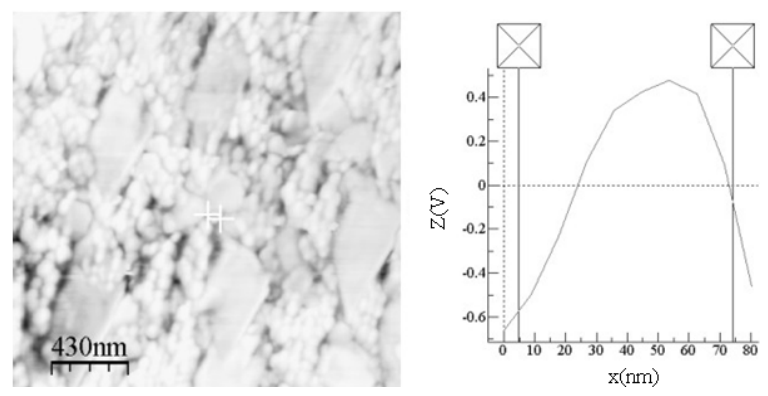

Fig. 6: Line profile of apatite Nano particle Y-TZP for 7 days

Table 2: Element present on Y-TZP for 15 days SBF

\begin{tabular}{lll}
\hline Element & Wt (\%) & At (\%) \\
\hline OK & 28.31 & 63.80 \\
YL & 04.31 & 01.51 \\
PK & 10.32 & 08.34 \\
ZrL & 41.36 & 14.14 \\
CaK & 15.69 & 12.21 \\
\hline
\end{tabular}



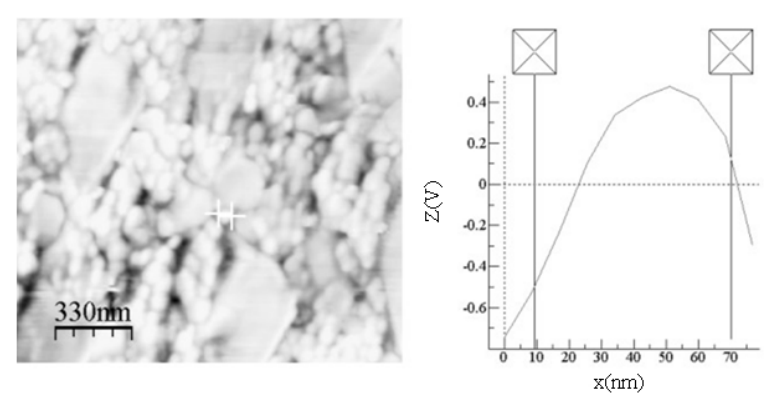

Fig. 7: Line profile of apatite Nano particle on Y-TZP for 15 days

\section{RESULTS AND DISCUSSION}

The phase transformation of zirconia from tetragonal to monoclinic structure was based on the reaction with water and leads to the formation of $\mathrm{Zr}$ OHgroup (Castkova et al., 2004; Chevalier et al., 1999). Including $\mathrm{OH}$ and $\mathrm{COOH}$ group and nanostructure surface of zirconia, were thought to be the key to the bioactivity of biomaterials. Therefore it is possible that the $\mathrm{Zr}-\mathrm{OH}$ group generated during phase transformation of zirconia substrate from tetragonal to monoclinic phase in water could act as the nucleation sites of apatite and the amount of $\mathrm{Zr}-\mathrm{OH}$ on the surface of zirconia substrate also affected the solution. In addition, the nanostructured surface of the zirconia substrate was also thought to play an important role in its bioactivity. The deposition of calcium ions is the first and most crucial step of carbonate containing hydroxyapatite nucleation from an ionic solution. This process is believed to initiate the growth of bone like apatite on the surface biocompatible implants.

\section{CONCLUSION}

The effect of chemical treatment with aqueous $\mathrm{H}_{3} \mathrm{PO}_{4}$ on zirconia and found that the $\mathrm{Zr}-\mathrm{OH}$ group produced by chemical treatment improved the bioactivity of the material and that the $\mathrm{Zr}-\mathrm{OH}$ group formed on zirconia after pre heat treatment in $5 \mathrm{M}$ $\mathrm{H}_{3} \mathrm{PO}_{4}$ aqueous solution showed the ability to induce apatite formation in simulated body fluid. Bioactive 3Y-TZP substrates were obtained using a biomimetic method consisting in the immersion of the Samples in SBF for 7 days, followed by the immersion in SBF for 15 days. An amorphous calcium and phosphate layer was observed on the biomimetically-treated samples with bioactive systems. However, elaborated characterization indicates that this Ca-P layer consists of nano crystals apatite that has a defective structure and very low crystallinity. These features are in fact, very similar to those of the mineral phase in bone and hence bone producing cells, that is osteoblasts, can preferentially proliferate on the apatite and differentiate to form an extracellular matrix composed of biological apatite and collogen. This is due to the long time immersion of the specimen in SBF solution.

\section{REFERENCES}

Benzaid, R., J. Chevalier, M.M. Saadaoui, G. Fantozzi and M. Nawa et al., 2008. Fracture toughness, strength and slow crack growth in a ceria stabilized zirconia-alumina nanocomposite for medical applications. Biomaterials, 29: 3636-3641.

Cales, B., 2000. Zirconia as a sliding material. Clin. Orthop. Relat. Res., 379: P94-112 DOI: PMID: 1103979

Castkova, K., H. Hadraba and J. Cihlar, 2004. Hydrothermal aging of tetragonal zirconia ceramics. Ceramics-Silikaty, 48: 85-92. http://cat.inist.fr/?aModele $=$ afficheN\&cpsidt $=1653$ 894

Chevalier, J., B. Cales and J.M. Drouin, 1999. Low temperature aging of Y-TZP ceramics. J. Am. Ceram. Soc., 182: 2150-2154. DOI: 10.1111/j.1151-916.1999.tb02055.x

Clarke, I.C., M. Manaka, D.D. Green, P. William, G. Pezzotti and Y.H. Kim, 2003. Current status of zirconia used in total hip implants. J. Bone Joint Surg. Am., 85: 73-84.

Kosmac, T., C. Oblak, P. Jevnikar, N. Funduk and L. Marion, 2000. Strength and reliability of surface treated Y-TZP dental ceramics. J. Biomed. Mater. Res. (Applied Biomater.), 53: 304-313. DOI: ci.nii.ac.jp/naid/10021031537/e

Liu, X.Y. and C.X. Ding, 2003. Bioactivity of plasma sprayed wollastonite/zirconia composite coating. Surface Coat. Technol., 172: 270-278.

Ohtsuki, C, T. Kokubo and T. Yamamuro, 1992. Mechanism of apatite formation on $\mathrm{CaO}-\mathrm{SiO}_{2}-\mathrm{P}_{2} \mathrm{O}_{5}$ glasses in a simulated body fluid. J. Non-Crystal. Solids, 143: 84-92.

Uchida, M., H. Kim, F. Miyaji, T. Kokubo and T. Nakamura, 1998. Apatite Forming Ability of Zirconia Gel in Modified SBF Solutions. In: Corporation Private Limited Bioceramics, Legeros, R.Z. and J.P. Legeros (Eds.), Vol. 11, World Scientific Publishing, Singapore, USA., pp: P77-80.

Uchida, M., H. Kim, T. Kokubo, F. Miyaji and T. Nakamura, 2001a. Bonelike apatite formation induced on zirconia gel in a simulated body fluid and its modified solutions. J. Am. Ceram. Soc., 84: 2041-2044. DOI: $10.1111 / \mathrm{j} .1151-$ 2916.2001.tb00955 
Uchida, M., H. Kim, T. Kokubo, F. Miyaji and T. Nakamura, 2001b. Bonelike apatite formation induced on zirconia gel in a simulated body fluid and its modified solutions. J. Am. Ceram. Soc., 84: 2041-2044. DOI: 10.1111/j.1151-2916.2001.tb00955.X

Uchida, M., H.M. Kim, T. Kokubo, M. Nawa, T. Asano, K. Tanaka and T. Nakamura, 2002. Apatite forming ability of a Zirconia/Alumina nano composite induced by chemical treatment. J. Biomed. Mater. Res., 60: 277-282. DOI: 10.1002/jbm.10071
Yan, Y.Y. and C. Lu, 2009. Ultraviolet enhanced bioactivity of zirconia films prepared by micro arc oxidation. Thin Solid Films, 517: 1577-1581. 